\title{
Management and legal regulations for the practice of precision and organic agriculture
}

\author{
Vladimir Matveev ${ }^{1 *}$, Varvara Dikareva ${ }^{2}$, and Alfia Larkina $^{3}$ \\ ${ }^{1}$ Institute of Legislation and Comparative Law under the Government of the Russian Federation, \\ Cheremushkinskaya str., 34, Moscow, 117218, Russia \\ ${ }^{2}$ Moscow State University of Civil Engineering, 26, Yaroslavskoye shosse, Moscow, 129337, Russ \\ ${ }^{3}$ Moscow State University of Technology and Management named After K.G. Razumovsky (the First \\ Cossacs University), 73, Zemlyanoy val, Moscow, 109004, Russia
}

\begin{abstract}
This study presents an integrated approach to managing a modern agricultural enterprise. New digital technologies used in agriculture make it possible to optimize the processes of land cultivation, sowing, calculation and application of fertilizers, as well as harvesting. Satellite positioning system (GPS), automated steering system, remote sensing, and geo-mapping used in the complex can significantly increase the productivity and profitability of agricultural industry.
\end{abstract}

\section{Introduction}

Minimizing the use of synthetic fertilizers and plant growth regulators, as well as feed additives in animal husbandry has become a trend in modern agriculture in most countries of the world. Significant increase in the cost of the final organic product is seen as a logical investment in consumer health. In the long term, organic agriculture should support the health of the world's population and the sustainable functioning of agribusiness [1,2].

In addition to the traditional use of organic fertilizers and crop rotation methods, the latest scientific advances make a significant contribution to the effective development of organic agriculture.

Thus, organic agriculture combines tradition and science to improve the environment and improve the quality of agricultural and products. This implies scientific research of ecosystems and biogeochemical cycles of substances and elements [3-5].

\section{Principles of biological synergy:}

- $\quad$ refusal to use synthetic fertilizers and antibiotics

- $\quad$ using organic fertilizers (animal and plant ones)

- $\quad$ using crop rotation for soil restoration;

- $\quad$ application of biological methods of plant protection;

- using a closed cycle "crop production - feed, cattle farming - fertilizers"

The goal of any agricultural enterprise is to produce more food in the same area and with maximum resource savings. That is, the goal is to optimize the productivity and profitability of agriculture

\footnotetext{
${ }^{*}$ Corresponding author: a.copytowa@yandex.ru
} 


\title{
2 Precision agriculture technologies
}

Over the past 10 years, the technological component of farms has undergone significant improvements. First of all, these are digital technologies and GPS - navigation.

Precision agriculture is defined as "a management strategy that gathers, processes and analyzes temporal, spatial and individual data and combines it with other information to support management decisions according to estimated variability for improved resource use efficiency, productivity, quality, profitability and sustainability of agricultural production". This definition was given to precision agriculture by the International Society of Precision Agriculture.

The goal is to develop a set of technologies to reduce the cost of precision agriculture, the aim of which is to use digital technologies to irrigate and fertilize only those crops that really need them at that point in time.

Precision agriculture is a holistic approach that involves integrating precision agriculture methods to achieve maximum productivity with minimal resources.

The most important technological aspects of precision agriculture are presented in Fig. 1

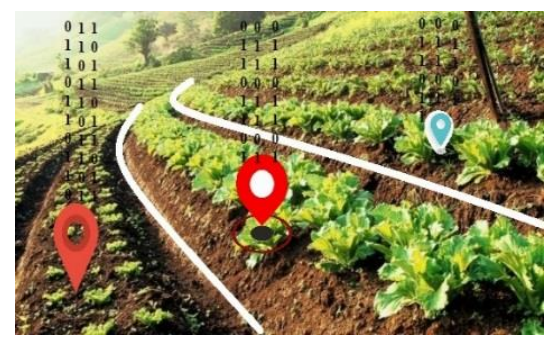

- Global Satellite Positioning System

- Remote Sensing

- Variable Rate Technology (VRT)

- Automated Steering System

○ Geo-mapping

- Data management system

- Advanced agricultural machinery

Fig.1. Precision agriculture methods

\subsection{Global Satellite Positioning System}

Satellite imagery is very important in precision agriculture, which uses remote sensing and satellite imagery to increase yields and reduce production costs. Satellite imagery can be used to map large areas of land and track changes in soil and crop conditions over time, as well as to detect and monitor the presence of pests. (Fig. 2, 3)

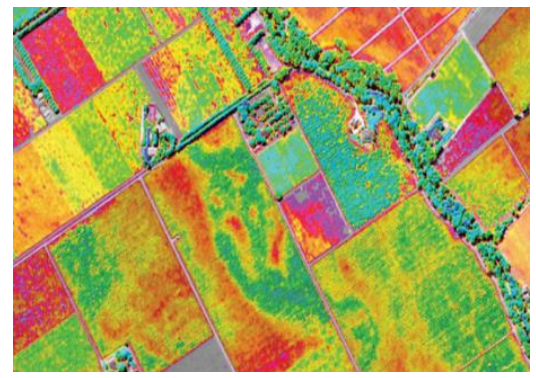

\author{
Satellite image \\ - Green areas show healthy crops \\ - Red areas show unhealthy crops
}

Fig. 2. Mapping of agricultural land. 


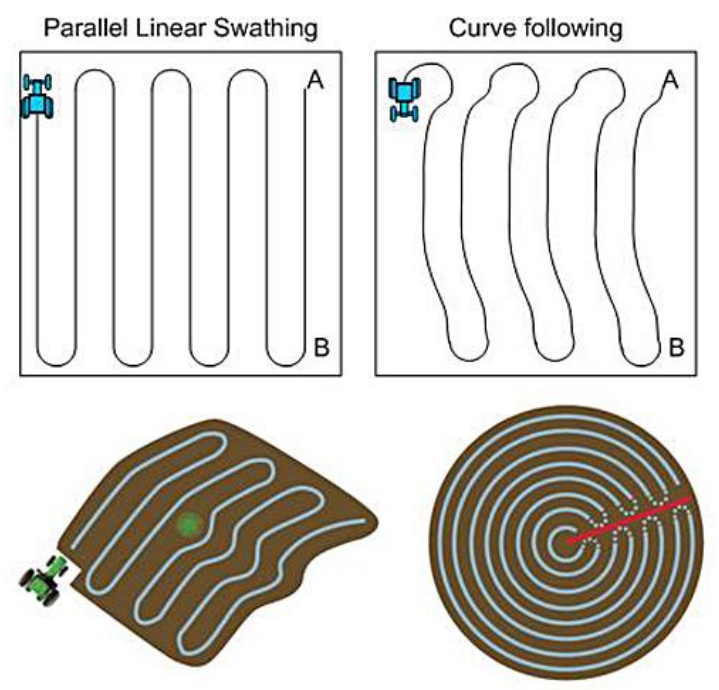

Fig. 3. Field traffic patterns that GPS navigation can follow. Source: http://precisionagricultu.re

\subsection{Automated Steering System}

This system reduces human errors. The automatic steering system allows controlling the movement of the vehicle, while excluding uncovered areas of the field (for example, at the edges and at the corners of the movement of agricultural machinery), as well as excluding "overlapping" areas.

The types of automated steering systems differ in the level of accuracy in the field work. The most accurate is a centimeter-based system based on a local station with real-time kinematic (RTK) differential correction.

\subsection{Variable Rate Technology (VRT)}

Variable rate technology allows the human operator to control the amount of seed, fertilizer, water for irrigation. Thanks to this technology, optimal planting density and economical introduction of nutrients and plant protection substances into the soil are obtained.

The combination of these two systems - Automated Steering System and Variable Rate Technology - allows achieving the rate of application of the required resources at a certain place in the field, which allows achieving a significant economic effect.

\subsection{Precision Geo-Mapping}

Precision Geo-Mapping allows creating maps of soils and crops, taking into account soil type, soil $\mathrm{pH}$, presence of pests and others. Soil maps are generated by sensors attached to the vehicle or using remote sensing drones and satellites. Combined with GPS, these sensors collect data to assess soil and crop conditions and assign this information to specific areas of the field in order to continuously monitor changes in soil and crop conditions.

\section{Land Fund Management}


By their intended purpose, lands in the Russian Federation are divided into the following categories:

1. agricultural land;

2. lands of settlements;

3. industrial lands, lands for energy, transport, communications, radio broadcasting, television, informatics, lands for space activities, defense, security and other special purpose lands;

4. lands of specially protected areas and objects;

5. lands of the forest fund;

6. lands of the water fund;

7. stock lands.

The lands are used in accordance with the designated purpose. The legal regime of lands is determined based on their belonging to a particular category and permitted use in accordance with the zoning of territories, the general principles and procedure for which are established by federal laws and the requirements of special federal laws.

The types of permitted use of land plots are determined in accordance with the classifier approved by the Russian federal executive body responsible for the development of state policy and legal regulation in the field of land relations.

The transfer of land from one category to another is carried out in relation to:

1) federal land - by the Government of the Russian Federation;

2) land owned by constituent entities of the Russian Federation and agricultural land owned by municipalities - by the executive authorities of constituent entities of the Russian Federation;

3) land in municipal ownership, with the exception of agricultural land, - by local governments;

4) privately owned land:

- agricultural land - by the executive authorities of the constituent entities of the Russian Federation;

- lands of other purpose - by local authorities.

The transfer of land from settlements into land of other categories and land of other categories into land of settlements, regardless of their form of ownership, is carried out by establishing or changing the boundaries of settlements in the manner established by the Land Code and the legislation of the Russian Federation on urban planning.

According to the forecasts, the world's population will reach nearly 10 billion by 2050 . Against this background, we can say that food security is becoming one of the most important global challenges.

The federal law of the Russian Federation "On organic products and on amendments to certain legislative acts of the Russian Federation", developed by the Ministry of Agriculture of Russia, entered into force on January 1, 2020. The technologies used in the production of organic products are significantly different from those used in traditional agriculture. In particular, the use of chemicals, pesticides, antibiotics, animal growth stimulants, hormonal preparations, and genetic modification is limited or completely excluded. The labeling of organic products provided for by the Law includes a combination of inscriptions and a standard graphic image (sign) of organic products on the packaging and shipping containers of organic products, or on other information carriers attached to it or placed in it. The inscriptions used to label organic products may contain the word "organic", as well as its abbreviations or words derived from this word, alone or in combination with the name of organic products.

Figures 3, 4, 5 represent the structure of agricultural land in the Russian Federation, land fund of the Russian Federation, and farmland structure. 


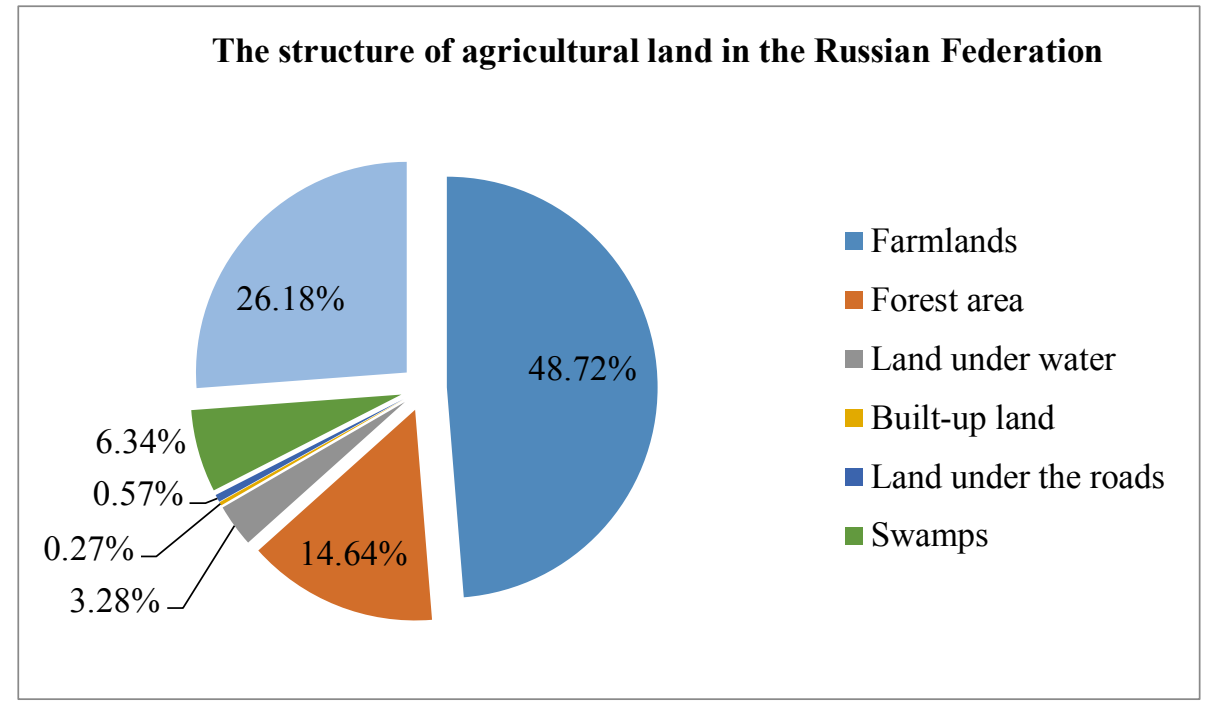

Fig 1. The structure of agricultural land in the Russian Federation

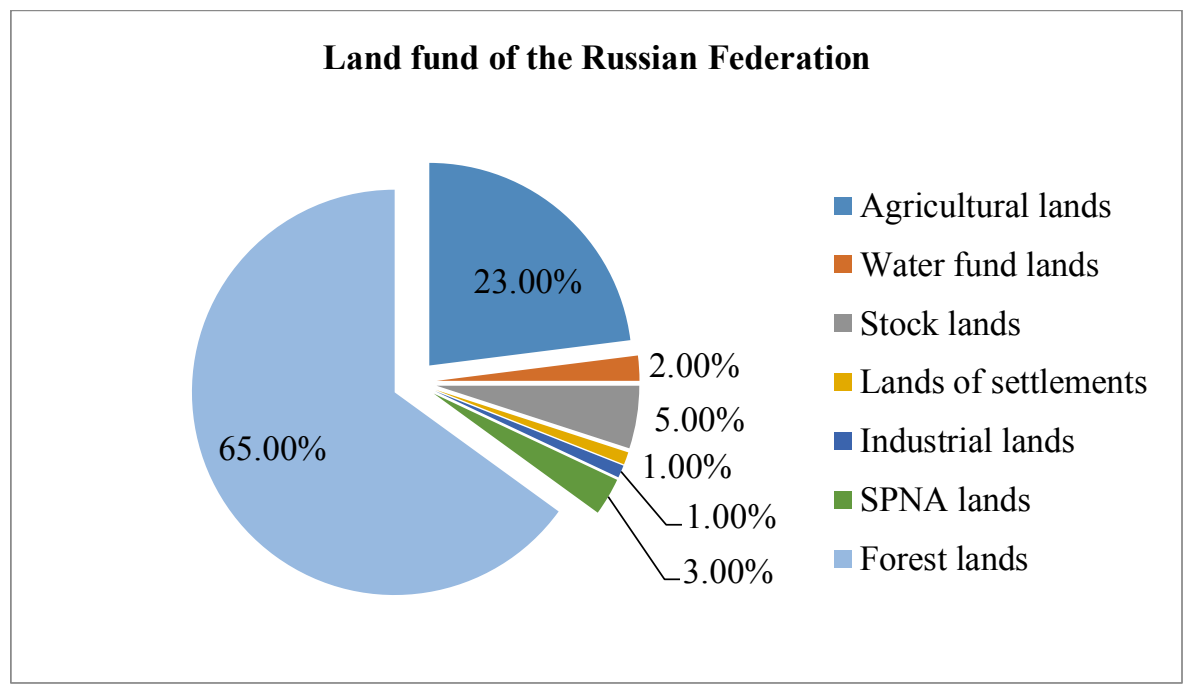

Fig 2. Land fund of the Russian Federation 


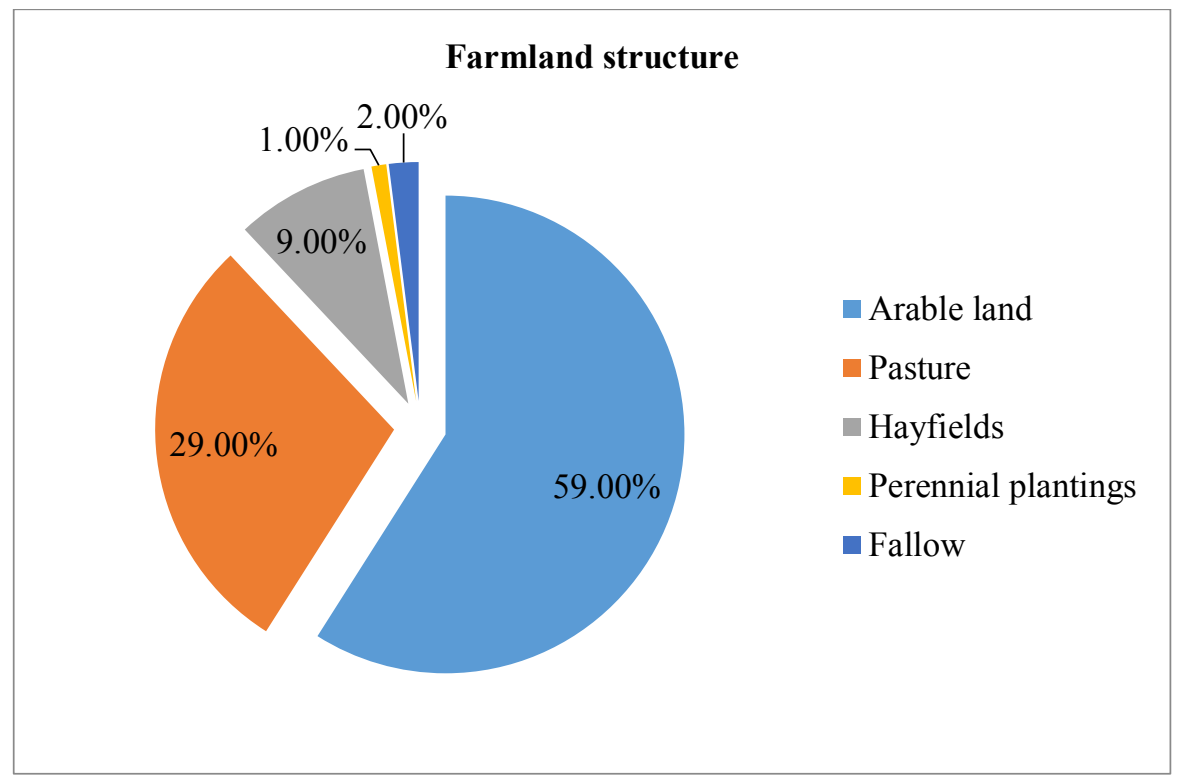

Fig 3. Farmland structure

\section{Conclusions}

Thus, precision agriculture methods can reduce production costs, improve soil conditions, and quickly respond to threats to crops. This, in turn, will lead to higher yields and better crop quality and, in general, to the sustainability of agricultural production.

\section{References}

1. P. Sarigiannidisa, Th. Lagkasb, I. Moscholios, Computer Networks, Volume 172, 107148, (2020), https://doi.org/10.1016/j.comnet.2020.107148

2. J. González-García, R. L. Swenson Alfonso, Gómez-Espinosa, Computers and $\begin{array}{lllll}\text { Electronics in } \quad \text { Agriculture, 177, } & \text { 105695, }\end{array}$ https://doi.org/10.1016/j.compag.2020.105695

3. Liang Yu, Hong Qin, Ping-an Xianga, Sustainable Computing: Informatics and Systems, Vol. 28, 2020, 100423, https://doi.org/10.1016/j.suscom.2020.100423

4. Yuliana Griewald, Ecological Economics, Volume 151, 1-9, (2018), https://doi.org/10.1016/j.ecolecon.2018.04.026

5. V. Prishchepova, D.Müller, M. Dubinin, et al. Land Use Policy, Volume 30, Issue 1, 2013, 873-884, https://doi.org/10.1016/j.landusepol.2012.06.011 